\title{
Challenges of Potable Water Supply in Assosa Town, Benishangul Gumuz Region, Ethiopia
}

\author{
Sisay Mekonnen Haftom Kahsay \\ Department of Soil and Water Resource Management, Assosa University, College of Agriculture and Natural \\ Resource, PO box 18, Assosa, Ethiopia
}

\begin{abstract}
Assosa town has been through a problem of sustainable potable water supply because the demand is not satisfied and large numbers of people do not have access to adequate amount of potable water. As a result, residents are forced to get water from unprotected sources which are far from their homes. Besides, they also buy water frequently from illegal persons and incur additional cost. In line with these the main objective of this study was to assess the challenges inadequate water supply in Assosa town. A survey was conducted on a randomly selected 97 House Holds and interviews with purposefully selected key informants in the year 2019. Emphasis was put on examining the nature of the problems of water supply and challenges the service providers and households faced. The study has confirmed that the town water supply service could not cover the demand of it with present existing capacity and based on the research outcome only $36.1 \%$ of the respondents get water through their own private taps. As the majority of respondents were agreed that in the study area, many respondents expressed that population size, budget problemsand insufficient and poor distribution of water were the main challenges for potable water supply system. That is, the water supplying service in the town is unsustainable; it is socially inequitable, economically inefficient and environmentally unsound. This study presents the following recommendations to ensure sustainable water supply in the study area including providing different water sources, conserving water sources, family planning, demand management, demand oriented supply, participating different actors, mobilizing financial resources, and staffing organizational structure with skilled personnel and equipping it with material facilities.
\end{abstract}

Keywords:Water sources, production, accessibility, potable water supply, Assosa.

DOI: $10.7176 / \mathrm{JRDM} / 75-03$

Publication date:May $31^{\text {st }} 2021$

\section{Back Ground and Justification}

The sustainable provision of adequate and potable drinking water is the most important of all public services. It is one of the essential necessities of life next to oxygen.Man animal and plant cannot exist without it. Man can live without shelter and clothing for some time, but without water it soon perishes. Particularly, of any region in the world, the problem of water supply is deep rooted andmulti-dimensional in Africa. In the year 2000, World Health Organization (WHO, 2000) estimated that Africa contains $28 \%$ of the world's population without access to improvedwater supplies. Even though Africa is stated that it is currently urbanizing rapidly and by 2020 it is expected that over $50 \%$ of the population in Africa will reside in urban areas,more than $30 \%$ of the residents in urban areas currently lack access to adequate waterservices and facilities (WUP, 2003).Ethiopia is believed to be the water town of east Africa because almost all rivers of Ethiopia originated from it and contribute huge amount of water potential to neighbouring countries .but the estimated water supply level in terms of coverage ,quantity and reality is among the lowest in the world. However similar to the urban water sector in many developing countries there are serious constraints in meeting the challenge to provide adequate water sustainably for all urban residents in Ethiopia. Water supply shortages and quality deteriorations are among theproblems which require greater attention and action. Various strategies are alwaysbeing developed to make water accessible to all inhabitants. However due to insufficient structures coupled with rapid population growth and urbanization, the gap between demand and supply of water continues to widen (Degnet, 2011). These effects of the poor water supply facility in the country have high impact on the economic development of the country and the living conditions of the town's communities (Aycle, 2003). The situation in the study area is not different from such realities.

Water is one of the most crucial and non-substitutable environmental resources. Adequate, quality, safe and affordable supply of drinking water is a basic need forhuman life. However many people across the planet do not have access to safe andadequate water supply services which affects their life in various ways (Yibeltal, 2011).The provision of adequate clean drinking water in the study area has been through challenging situation especially in the current time. Assosa town water supply and sanitation service office, the legitimate body to supply water for the town, had many problems as an institution to ensure a sustainable water supply due to different challenges such asbudget shortage, lack of manpower to handle policy and regulatory issues and to plan, operate and maintain the service, poor institutional organization and lack of coordination with stakeholders were some of them. Also the problem of water supply in the town is not only the problem of distribution and 
reliability but also it has the problem of adequacy and accessibility. Therefore, in the light of the aforementioned problems, this study was carried out to assess the challenges of sustainable water supply in Assosa Town, Benishangul Gumuz, Region, Ethiopia.

\section{Methods and materials}

\subsection{Description of the study area}

Assosa town is a town in western Ethiopia and the capital of the Benishangul-Gumuz Region of Ethiopia. Located in the Asosa Zone, this town has a latitude and longitude of $10^{\circ} 04^{\prime} \mathrm{N} 34^{\circ} 31^{\prime} \mathrm{E}$, with an elevation of 1,570 meters.) The climate of the study area is characterized by tropical or humid hot weather having distinct dry wet seasons. The average temperature in Assosa is $21.9^{\circ} \mathrm{C}$. The rain fall of the area usually gets rain starting in May and ending in October. In a year, the average rainfall is $1,222 \mathrm{~mm}$ (National Meteorology Agency \& WMO, 2013). The total population of the study area 33,671 of these 16,720 are males, 16,951females and 7,033 are the total household in the study area.

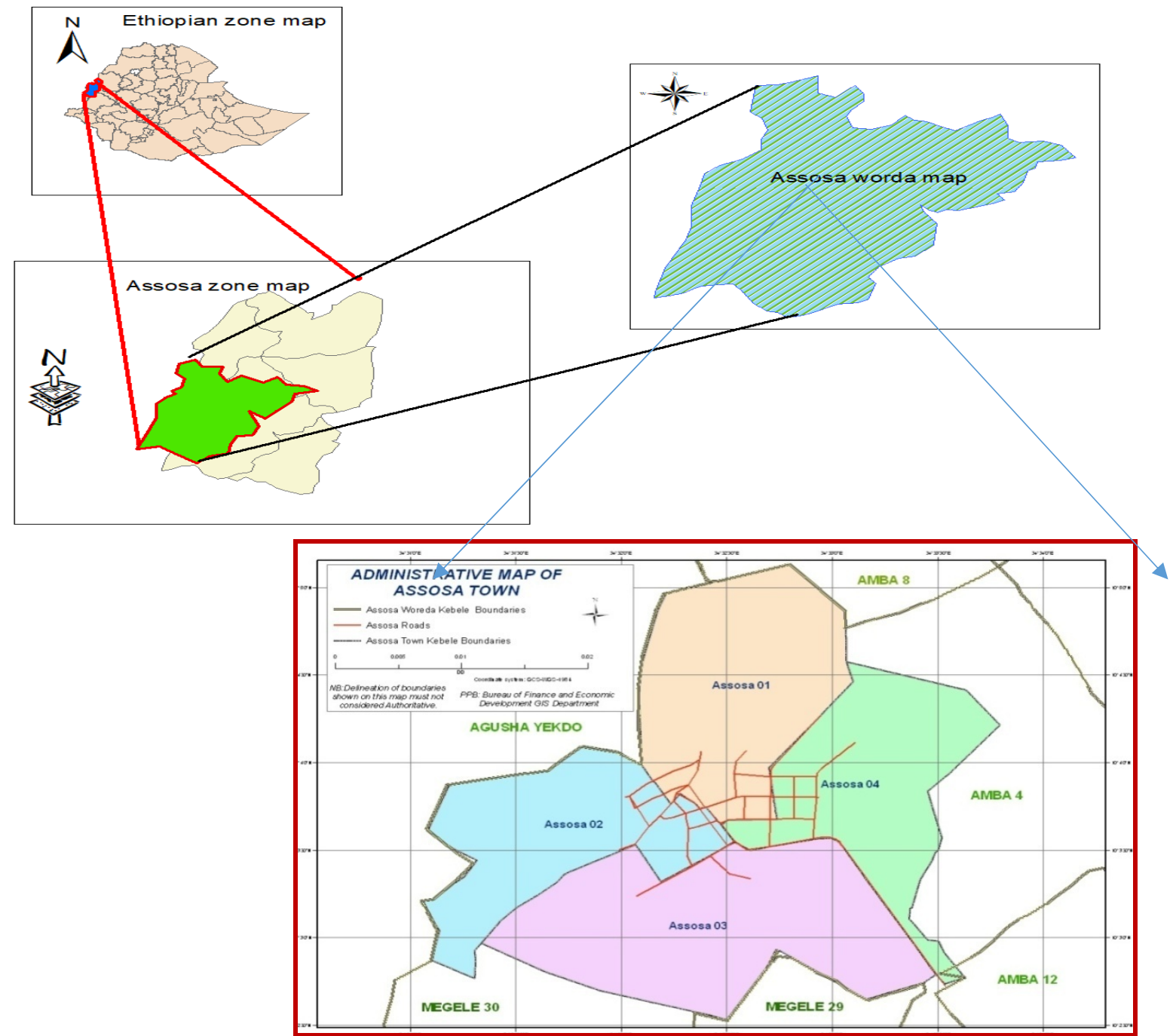

Figure 1: Map of the study area Assosa town (Source: Ethio GIS)

\subsection{Source and type of data}

The primary data was collected from sample households and Key Informant Interview whichwas made with various stakeholders, community representatives, water service officers, City Administration and other concerned and affected bodies. In addition, personal observation with users werealso the other data sources which reinforced the required data from the study area and served as a check for data reliability. The secondary data was collected from published materials such as book magazine, bleus paper and also from agricultural offices of Woreda. 


\subsection{Sample size and Sampling Techniques}

One of the central objectives of this researchwas to investigating the sources of water supply and its challenges in Assosa Town; to this end to get the representative population and the necessary information accordingly; this research used the combination of random and purposive sampling techniques to select household respondents and Key Informants. Random sampling wasapplied to select the sample households to get representative informants whereas purposive sampling wasused to select the sample ketenas and Key Informants. To carry out the study twoketenes were selected in the study area based on the current administrative division system. The sample ketenes were ketena 01 \&ketena04. Those ketenes were selected to participate in this study depending on different ways, including size, population, living standard, socio-economic status of households, nature of water usage and water sources. Ketena04 was one of the ketena which is containing poor households, old settlements, and new settlement and also the ketene is one of the populous ketenas. Therefore the ketenas were purposively selected.In general the study covered only 97 households from a total of 3,248 households of the selected ketenes and in each ketene every $\mathbf{i}^{\text {th }}$ household was selected for the study. As to the sample size determination, from among different methods, the one which was developed by Carvalho (1984), as cited by Wonduante (2013), was used (see table 1 below).

Table1: Sample size determination

\begin{tabular}{llll}
\hline Population size & \multicolumn{2}{c}{ Sample size } \\
\hline & Low & Medium & High \\
$51-90$ & 5 & 13 & 20 \\
$91-150$ & 8 & 20 & 32 \\
$151-280$ & 13 & 32 & 50 \\
$281-500$ & 20 & 50 & 80 \\
$501-1200$ & 32 & 80 & 125 \\
$1201-3200$ & 50 & 125 & 200 \\
$3201-10000$ & 80 & 200 & 315 \\
$10001-35000$ & 125 & 315 & 500 \\
$35001-150000$ & 200 & 500 & 800 \\
\hline
\end{tabular}

Source; Carvalho (1984), Wonduante2013,Taking into account the resemblance of the sample ketena, resource and time limitation, a sample size of 97 which was in between the low and medium sample sizes were applied.

\subsection{Data collection Techniques}

Data on factors that may hinder the sustainable functioning of water supply schemes weregathered through employing multiple methods including Questionnaire, Interview and personal observation vigorous instruments to directly observe the existing water supply problems in the study area. Primary data related with the socioeconomic characteristics of the respondents, demand responsiveness and sustainability factors of the service, type of participation of beneficiaries and women, issue of cost sharing and recovery, communitytraining and awareness creation, level of consumer satisfaction for the service provided, physical condition of water supply points under study, willingness of beneficiaries to sustain the system, repair and maintenance for the water supply services, technical and institutional issues werecollected through structured questionnaires. It was mainly employed to gather data related with the presence of pipe lines in selected households, to check the presence of water at any time, the areal coverage of water pipe lines and the factors behind some varieties like location and altitude. It was carried out through the help of checklists according to the objectives of the study. Key informant interview was conducted with the town's residents from different offices, like Ketenaleaders, with persons of different responsibilities, knowledge and experience about the town's water coverage, the balance between demand and supply of water in the town, major challenges facing in the provision of the service, level of community awareness and participation in the provision of the service.These key informants were purposively selected from different offices assuming that they have deep and relevant information from their official responsibilities and continue involvement about the issues.

\subsection{Data Analysis Method}

The collected data was analysed by using descriptive statistics like mean, median, percentage and frequency and it was displayed mainly through tables and graphs. In part of the paper an attempt was made to present and interpret data occurring the relationship between water supply against household's size, income and that of distance from the sources of water. Statistical Package Social Science (SPSS) was utilized to analyse all the data of this study.

\section{Results and discussion}

This chapter mainly focuses on the data that has been collected through questionnaire, interviews, observation and document analysis. The data presentation and discussion procedure were mainly focused on the 
characteristics of the respondents, the existing water supply service, causes and challenges of water supply systemshortage in Assosa town. Urban domestic water supply is mainly the responsibility of AWSSS office of the town.

\subsection{Characteristics of the Surveyed Households}

According to table 2, the sampled respondents based on sex 43(44.3\%) were males and $54(55.7 \%)$ were females from total sample households .Concerning usage of water, morewater was consumed by female compared to male. The proportion of water consumption ishigher among female population. Like for frequent usage of water for washing clothes, bathing and personal hygiene. Becauseof this high numbers of female respondents were purposively selected.

As per table 2, marital status of respondents, out of 97 Household heads in sampledpopulation, 31 (32\%) were single, $46(47.4 \%)$ were married, $9(9.3 \%)$ were divorced and11 (11.3\%) were widowed. Therefore, majority of respondents were married and familyresponsible takers. So, selected respondents regarding of marriage status they understoodproblems of water supply in detail and gave expected data for this study.

Table 2: Sex, Marital status of respondents

\begin{tabular}{|c|c|c|c|}
\hline Variable & Categories & Frequency & $\begin{array}{l}\text { Percent } \\
(\%)\end{array}$ \\
\hline \multirow[t]{3}{*}{ 1. Sex of the respondents } & Male & 43 & 44.3 \\
\hline & Female & 54 & 55.7 \\
\hline & Total & 97 & 100.0 \\
\hline \multirow[t]{5}{*}{ 2. Marital status of therespondents } & Single & 31 & 32.0 \\
\hline & Divorced & 9 & 9.3 \\
\hline & Married & 46 & 47.4 \\
\hline & Widowed & 11 & 11.3 \\
\hline & Total & 97 & 100.0 \\
\hline
\end{tabular}

Source: Author's survey, 2019

According to table 3 , the education background of the respondents $11(11.3 \%), 41(42.3 \%), 17(17.5 \%)$, and $28(28.9 \%)$ the education level of respondents was illiterate, grade 1-8, grade 9-12 and diploma and above respectively. Therefore, education is one of the determinants that is directly related with consumption and demand of water. High education level tends to demand for more water needs, due to awareness about health, hygiene and all other living conditions as additionally absorbed by researcher in the field. With respect to the age distribution of the respondents, 20(20.6\%), 29(29.9\%), 30(30.9\%), and 18(18.6\%) were in age between 18 to 30 , 31 to 40,41 to 50 and 51 and above year respectively. The majority of the respondents' ages were in between 41 to 50. Thus, indicates that the age level of respondents' awareness and who could know about problems properly and they could give expected answer for concerning the current provision of water supply.

Table 3: Education and Age of the respondents

\begin{tabular}{lllc}
\hline No $\quad$ Variable & Categories & Frequency & $\begin{array}{l}\text { Percent } \\
(\mathbf{\%})\end{array}$ \\
\hline 1. Education Background & & 11 & 11.3 \\
of the respondent & illiterate & 41 & 42.3 \\
& $1-8$ grade & 17 & 17.5 \\
& $9-12$ grade & 28 & 28.9 \\
& diploma and above & $\mathbf{9 7}$ & $\mathbf{1 0 0 . 0}$ \\
2. Age distribution of the & Total & 20 & 29.6 \\
respondent & 18 to 30 & 29 & 30.9 \\
& 31 to 40 & 30 & 18.6 \\
& 41 to 50 & 18 & $\mathbf{1 0 0 . 0}$ \\
\hline
\end{tabular}

Source: Author's survey, 2019.

The respondents that have been asked to respond to the survey have different occupations. These include government employees, merchant, daily laborers, farmers' and others (pensioners and households that depend on other people for their survival). Accordingly, 28 (28.9\%) of them were merchants, 31 (32\%) were government employees which constitutethe dominant section, $16(16.5 \%)$ were daily laborers, $16(16.5 \%)$ were Retained and farmer and $6(6.2 \%)$ others. Therefore, these people's income base was agriculture and by the help ofmigration situation they got to attend trading. Further, their income sources were bothagriculture and trading this makes the supply situation worse and these condition add burdenfor the water supply bodies, this condition contributes for the growth of the town as additionalsuggestion collected by author from sampled households. 
Table 4: Livelihood of the respondents

\begin{tabular}{llll}
\hline No Variable & Categories & Frequency & $\begin{array}{l}\text { Percent } \\
\mathbf{( \% )}\end{array}$ \\
\hline 1. Livelihood of the respondents & Trade(merchant) & 28 & 28.9 \\
& Governmentemployment & 31 & 32.0 \\
& Retained & 8 & 8.2 \\
& farming & 8 & 8.2 \\
& daily labor & 16 & 16.5 \\
& Other & 6 & 6.2 \\
& Total & $\mathbf{9 7}$ & $\mathbf{1 0 0 . 0}$ \\
\hline
\end{tabular}

Source: Author's survey, 2019.

\subsection{Existing Water Supply Situation in Assosa Town}

In line with this, the existing water supply situation in Assosa town, the interviews made with the head of AWSSS revealed that, the existing water distribution has its own problems toovercome high amount of dwellers. Therefore, households' demand for private connectionwas very high and increasing from through time. However, the water supplies unable to copewith dwellers demand as a result its shortage at production, technical problem, lack ofawareness of people as owner of property, high population pressure, and old water supply systemand unequal distribution of pipeline in some part of the town makes difficult the provision ofwater supply. According to the results of the study conducted African Development Fund (ADF, 2005), access to water is a prerequisite for health and livelihood, which is why the MDG target is formulated in terms of sustainable access to affordable drinking water supply. The availability of improved and quality water supply and sanitation infrastructures werewidely recognized as an essential component for human rights, social and economic development. The demand for such resources in the third world has been increasing over time, as a result ofthe rising standard of living and the population increase resulting from natural growth, as wellas rural-urban migration. Under such circumstances, planning for efficient and equitable water supply systems in both the short run and long run is critical to ensure that the populationreceives adequate water supplies (Alebel, 2002). This situation is the same in Ethiopia asclearly mentioned earlier. The existing main water sources for Assosa Town have beenspring water and rivers that were unsafe and public and private tab were used by nearly half ofthe people but with different constraints, the provision of the services was not sustained in thisarea as author observed in the field.

\subsubsection{The Source of water supply}

Generally, people get water from two main sources these were piped system and/or non-pipedsystems. Pipeline water supply was the safest and reliable sources of water. That means nonpiped systems were unprotected and unsafe which included rivers, springs and otherunprotected source. Hence, as Assosa town was a new and fast growing town. The residents have been supplied with piped water. Similarly, the majority of sampled householdsin the study area got piped and other alternative source. The specific water source was not continuous and reliable for all water users. Therefore, the households used water from tapsprivate and public, spring, rivers, water venders and their combined supply. For fear ofshortage of provision of water supply, the alternative sources were used to meet their needsthrough different supply system as shown in the following figure 2 .

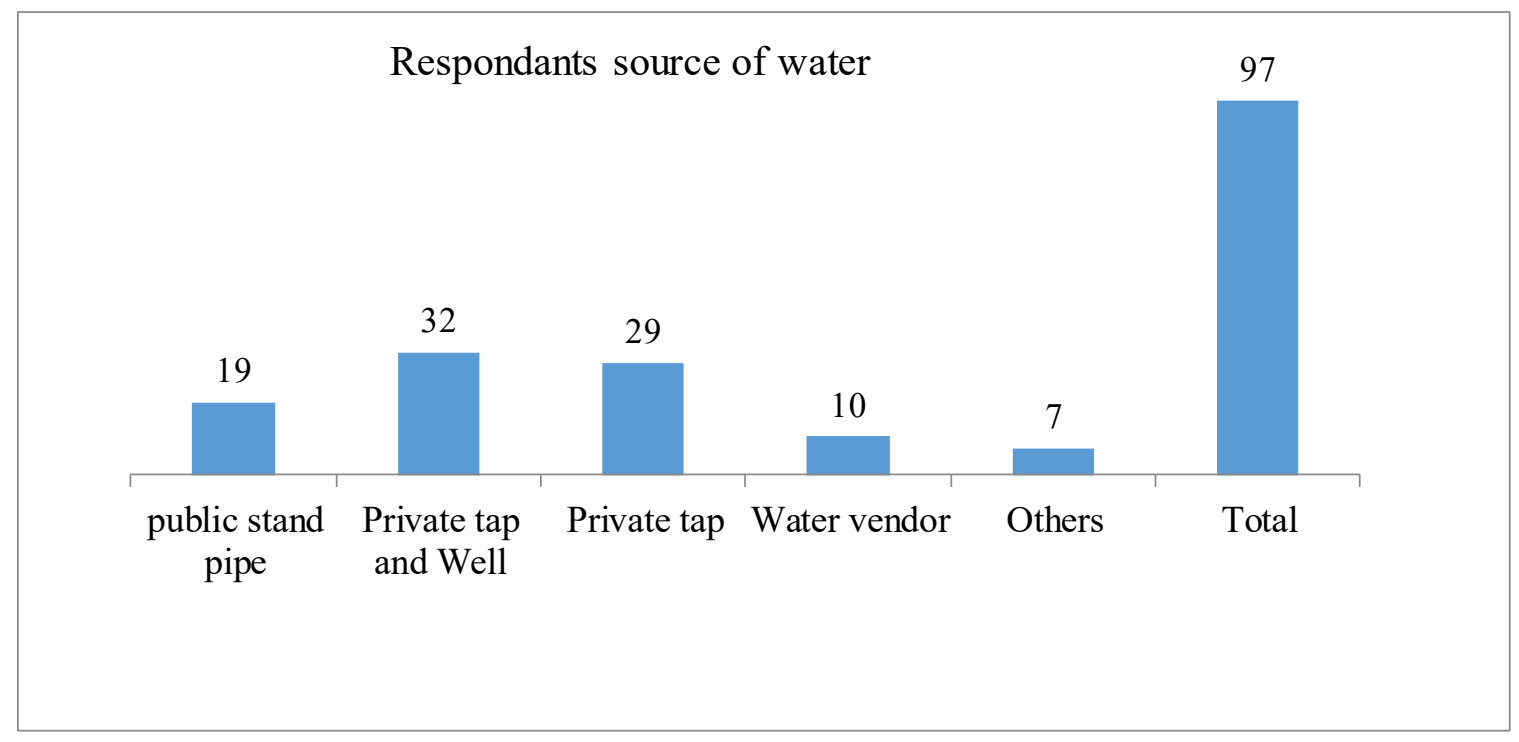

Figure 2: Sources of water for respondents 
According to the survey result as shown in the above figure 2, $29(29.9 \%)$ of the respondentshad access to drinking water through private tap connection, $19(19.6 \%)$ of the respondentshad access to water supply through public tap, $10(10.3 \%)$ of the respondents had access toconsumption water from water venders, $32(33 \%)$ of the respondents had access toconsumption water from well and private tap. The water supply and sewerage service (AWSSS) officers explained that the water supply problems in the town were due to different reasons. These were lack of financial capacity of WSSS office, inefficient support of other concerned body like municipality, water and mines energy office and the other administration body. Moreover, the awareness problems of the people in and around the town, high urban growth as a result of rural to urban migration, lack of preplan or forecast to minimize the water supply problems in the office. Further, there was a poor coordination and facilitation mechanism among the concerned bodies to encourage other stakeholders to support water projects in the area. These were aggravating the water problems in the study area.

\subsubsection{Access of water}

According to respondents result, access to safe water is a fundamental human need and a basic human right. Upholding the human right to water is an end in itself and a means for giving substance to the wider rights in the Universal Declaration of Human Rights and other legally binding instruments. These rights include the right to life, education, health and adequate housing. Ensuring that every person has access to at least 20 liters of clean water each day to meet basic needs is a minimum requirement for respecting the right to water and a minimum target for governments. Deprivation of clean water costs 1.8 million child deaths each year. For instance, as a result of Diarrhea, there are about 4,900 deaths globally each day, loss of 443 million school days each year from water-related illness. Moreover, women and children spend hours a day collecting water with high opportunity cost of time that would have been spent in education or employment (Mengesha et al., 2003; UNDP, 2006b). This will lead to water insecurity especially for those households with higher demand due to large family size (Collick, 2008). Similarly, in the study area with these circumstances of problem speed or shortages of water supply and population pressure after few years the shortage of water could affect health, economic activities as well as life of dwellers in the study area.

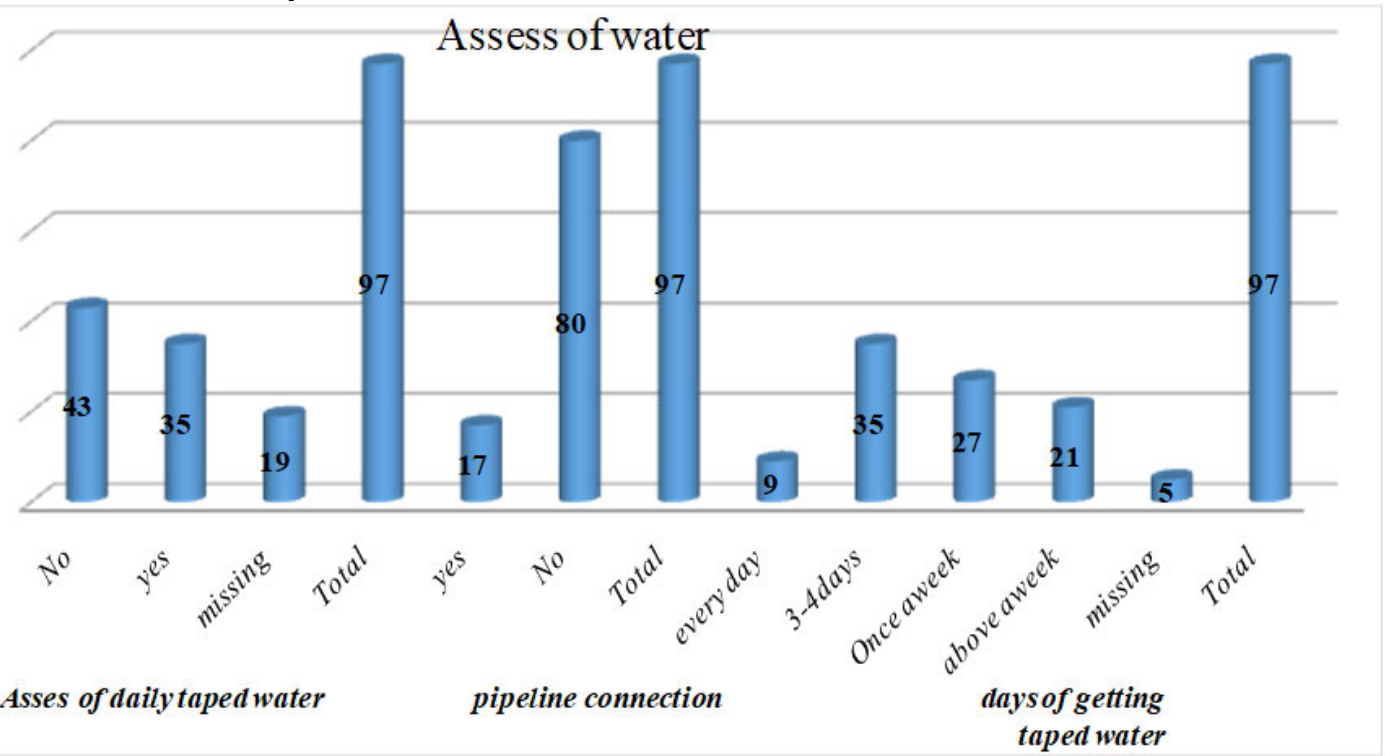

Figure 3: Access of water for respondents

As per figure 3, access of water supply service the household used indicate that almost half of the respondents did not use relatively piped water from the main source in the town. As item one indicates, out of 97 households $43(44.3 \%)$ of the respondents had no access to the pipelined water or have no pipeline connection and $35(36.1 \%)$ of the respondents have accessed pipeline connection to their home. This nearly large number of people indicated that the provision of water did not cover the demands of the water. Additionally, which reflect there was problems in the study area. So, the concerned body attention was low to improve or solve the water supply problems in the area as similar suggestion raised by sampled households.

\subsection{Challenges and causes ofinadequate potable water supply in Assosa town}

According to interview result, the challenges for water supply in the study area that involve topographic nature of town and population pressure as well as urban growth, economic development, behavior of the community in using water. As a result of this challenge demand for water increase time to time and this lead water supplies shortage in the study area. Particularly, population pressure in urban areas makes maintenance of the existing level of water supply a huge job. Water supply per capita declines as population increase beyond the planned 
ability. This forces either expansion of the existing water provision system or up warding new water supply sources which required long term investments.

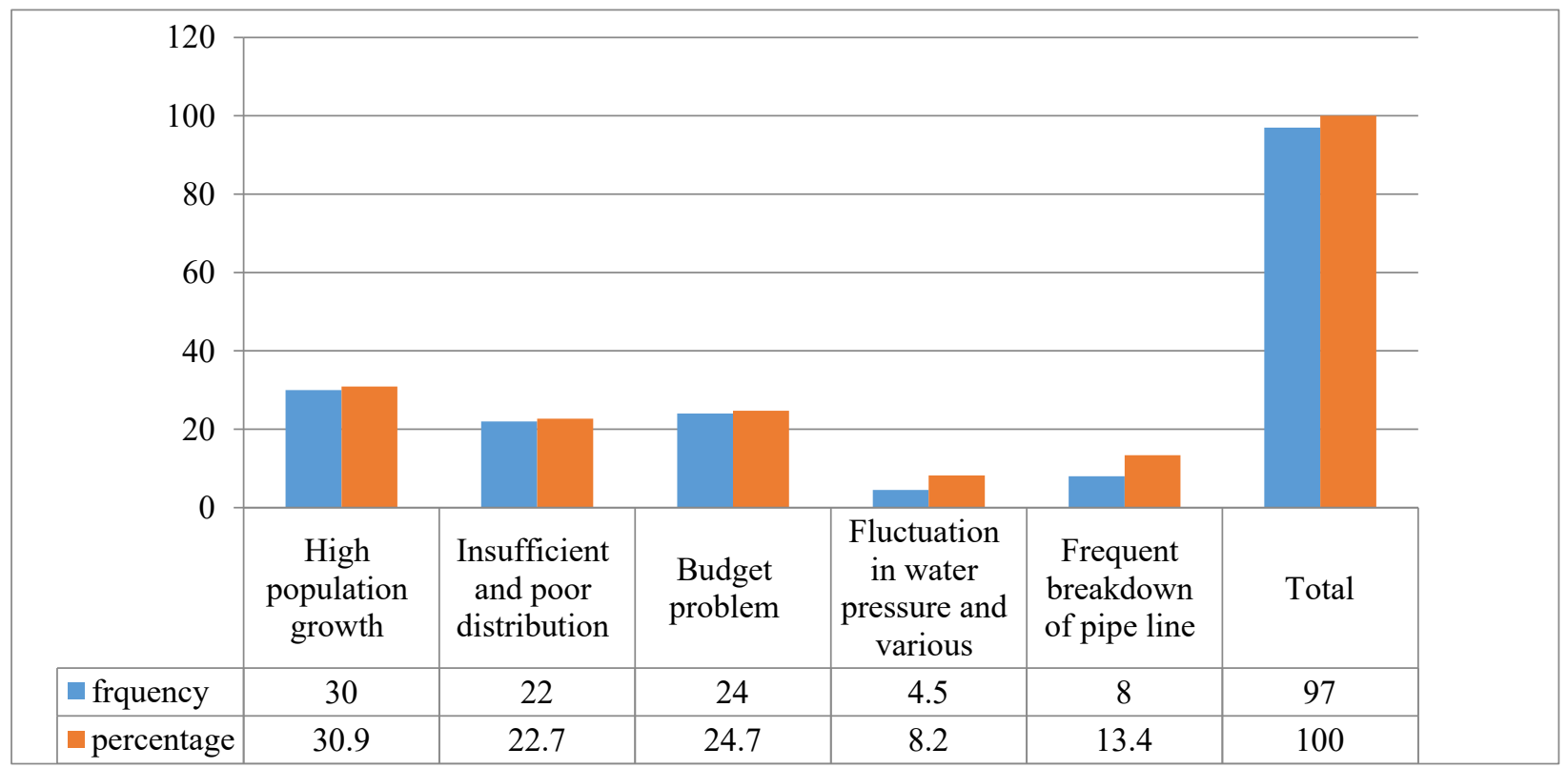

Figure 4: The challenges of potable water supply system for household consumption

In the above figure $4,30(30.9 \%)$ of the respondents expressed that population growth leads high demand of water because it is the most influencing factors that adds new demand on the service to meet their needs upon the services, $22(22.7 \%)$ said that the scarcity of water was due to insufficient and poor distribution of water infrastructure, $24(24.7 \%)$ of the respondents blamed budget problems of the water supply and sewerage services, $8(8.2 \%)$ of the respondents were fluctuation in water distribution and $13(13.4 \%)$ of the respondents explained the shortages of water as a result of frequent breakdown of pipeline. As the majority of respondents were agreed that in the study area, many respondents expressed that population size, budget problems and insufficient and poor distribution of water were the main challenges for potable water supply system. In line with this, many issues were raised during field observation from respondents of the town among this; mostly absence of physical infrastructure, ignorance by government agencies and municipality problem were challenges for potable water supply system in the town. Rapid growth of population: The steady growth of the town's population due to natural increase and migration coupled with the expansion of the town imposed higher burdenupon the utility office of Assosa town, WSS and it becomes difficult to accommodate the ever growing population. The problem is exacerbated by the failure to design optimum use of water for the town due to underestimation of population growth based on national population growth rate while the growth rate for Assosa is beyond that growth rate. Frequent supply interruption: There is a frequent interruption of the supply that reducedthe actual production less than the expected amount. In addition to this, the limitednumber of boreholes with decreasing water volume because of siltation has aggravated the situation. Unfair distribution of Water: It is also the other major problem in the town's WSSO. The rate of meter connection and the spatial distribution of public standpipes or water pointsdo not meet the demands of the community. The distribution system covers mainly the central part of the town; government built residential areas and the area where different organizations are concentrated. Most parts of the peripheral built up areas of the town are currently beyond the reach of the pipelines. When we see the spatial distribution of public stand pipes in the town, it is unfair. Their distribution in the older and central ketenas and in the new and peripheral built up areas is not proportional.

The problem of water Loss as a result of leakage is among the major causes of the widening gap between water demand and supply in the study area. In addition to the under capacity rate of production which lowers down the actual production of water supply, water loss has further reduced the amount of water supply that can reach the customers. This challenge is exacerbated by choice of inappropriate technologies that cannot meet appropriate standards. As observed from the field, in Assosa town water supply system still there are old pipes serving in distributing water. The expansion work on the town's sewerage system is also the other factor to the aforementioned problem. In many parts of the town the surface was dig and many pipe lines were broken. Plus to these causes the construction of cobble stone roads in the town's inner access roads has played its own significant role in the intensifying leakage problem. Unfair tariff and connection charges for the poor: The water tariff set by the Assosa WSS office and the Board of Assosa town water supply for private connection and its connection charges is unfair to the poor segments of the community. This is because of the fact that those who 
consume more volume of water pay low price due to the price set in this manner and also the high connection charges. This implies that the tariff subsidizes the urban rich, as they are the one that can afford and consume more than the poor and can also sell from their private matter for the poor at a higher price than the price they paid for WSS office. Limits to water consumption: Various physical and socioeconomic factors limited water consumption by households in Assosa town. To mention some of them: inadequate supply, the physical distance of housing units from water points, unreliable distribution due to weak pressure and frequent interruption etc. Among these factors, which limit the amount of water consumption, interruption of water supply is a more serious problem. During unexpected water supply interruption households encounter multidimensional problems as mentioned in the preceding sections. The growth of the town in terms of population, household size and income has also its own influence upon the water consumption by households.

\section{Conclusions and Recommendations}

The water supply of adequate quantity and acceptable quality is one of the basic needs of human beings, but the provision of potable water in Assosa town is inefficient. The situation is getting worse due to the population growth and spatial expansion of the town which outstripped its ability to supply sufficient water for its inhabitants. The existing sources of potable water are both surface and ground water which reach the customers or end users through Private meter connection and public water points. However, since the sources decrease in amount, especially during peak dry season, the amount of production is not adequate even for those who have access to it. The amount of production is also further reduced by less well working hours, limited number of boreholes and through losses including mechanical, frictional and head losses and leakage. Moreover, the state of water supply in the town in terms of coverage both in spatial and population, reliability, accessibility, and sustainability is not at the required standard.

The rate of private tap connection is low and the distribution system is inefficient. The major constraints of distribution systems identified are low density of pipeline networks, limited number of public water points and their unfair distribution, inadequate pressure in the pipe and the absence of well prepared maps for distribution pipelines. As a result, water consumption is affected in the town due to these physical factors and socioeconomic factors such as population growth, household income and size that affected their water consumption. Because of these poor functioning of the existing water supply service most of the households in the town are willing to pay higher prices for an improved water supply service if the government provides it. This prevalence of willingness to pay implies two things: there is further demand and the existing water supply service is not convenient for the customers. They have the ability to pay if water is provided in a relatively higher price than the current one. This shows that, WSS office could have been generated sizable revenue if it could provide a better water supply than the existing one. Hence, the problems of water supply in Assosa town are multidimensional in terms of both efficiency and equity. Among the challenges identified inadequate water supply, inequitable and inefficient distribution system, low coverage, unfair price and the resultant limited consumption are the major ones. These problems imposed different challenges on inhabitants such as loss of time, energy and money; exposure to waterborne and related diseases which penalizes the poor medical cost and pay high price for water vendors. The causes of these problems and challenges are to some extent resulted from management problems, under staffing, lack of sufficient funding and capacity and the absence of community, private, Community Based Organizations, and Non Government Organizations participation in the implementation of Water Supply Service activities.

In summary, while a sustainable water supply is one that considers customer selection of service type, equal distribution of water among various social groups, economic viability of different community members, meeting national and international drinking water standards, full participation of the society and presence of a well protected and functioning ecosystem, the situation in the study area is different. There are large number of people waiting for private meter connections in the suburban part of the town, travel long distances every day and take much time to fetch water the tariff does not charge the poor and riches fairly, there are no ways through which the community as a whole and women in particular to take part in the planning, implementation and decision making processes and at large there are no environmental protection and conservation works to provide water for the society at the required amount constantly. Therefore, the water supplying service in Assosa town in general is unsustainable; it is socially inequitable, economically inefficient and environmentally. Improving the existing water supply service in the town in terms of quantity, reliability and sustainability means upgrading the socioeconomic welfare of the people in the town. Thus, the following measures need to be taken to reverse the existing challenges: Conduct detail study on both underground and surface water to create a potential source of water supply if financial and environmental conditions allow, Design future water supply strategy based on demand orientation, i.e., self selection of the service type of customers rather than past trends and population figures; manage the demand by controlling waste or loss from pipe leakage and consumption through the use of meters and tariffs that are set in accordance with the volume of water consumption; Community participation in decision making: involving the community and CBOs at all levels of water supply program and allow private 
sector involvement in different components of water supply service such as provision of pipes, meters, equipments, machines etc. In addition to this, NGOs should take part in the rehabilitation of already constructed projects to minimize financial burden of the mandated agency, WSS office; mobilize resource: mobilize resources required to bridge the financial gap. This may include organizing donor's conference, meetings with individual donors and introducing water supply development program at meetings of the general public; Short term credit: since the poor segments of the urban community cannot afford the cost of meter connection charges, pipes, meters and other necessary inputs should be provided on the basis of short term credit in the form of either individual or group lending to enable the poor people to afford the services; Equitable distribution: water points and pipes ought to be evenly distributed in order to address the problem of the low income group. Moreover, reopening the closed ones (by giving them to organized small scale enterprises) and installing additional public water points would narrow down the gap between demand and supply taking into consideration the number of people, density and distance between water points; Conserving water resources: water resources should be conserved and recharged by the natural aquifer covering the water catchments with forests that can regulate water flow, reduce erosion and dam siltation and minimize reduction of water table; this refers waste curbing and reuse of wastewater for purposes such as gardening non-edible flowers, cleaning latrines and etc.;

Synchronization of water sources: water sources can be used for different purposes. Potable water can be used for drinking and cooking purpose while other sources such as traditional hand-dug well, river, spring and rain water can be used for clothes washing, animal watering, floor washing and bathing etc; Using water reservoirs: containers are the guarantee for frequent interruption of water supply. They solve the problem of complete absence of water supply by storing water. Therefore, it is important to agitate the community to have containers to overcome the absence of water supply especially during peak dry season; employing appropriate technology: appropriate technology that can meet appropriate standards and can have adequate spare parts and fittings should be applied. Even in the long term the use of solar energy rather than the current electricity would be appreciated. This can minimize the rate of interruption. Moreover, the advantage of using pit latrines rather than modern toilet facilities should be given due consideration as they do not need water after defecation and can save water consumption. But they should be spaced at a reasonable distance from water sources; ensuring the principles of optimal use of water: The available water should be equitably distributed to the community to ensure equity of access. This equitable distribution of water to the community not only ensures efficient use of water but also leads to consumption of water from homogenous sources and maintains sustainability of the source thereby curtailing its depletion.

\section{Reference}

African Development Fund (ADF), (2005). Ethiopian rural water supply and sanitation appraisal report. Infrastructure department north, east and south Report.

Alebele Bayrau, (2002). Affordability and Willingness to Pay for Improved Water Supply in Urban Areas. A Case Study of Nazareth Town, Ethiopia

Ayclekuths, (2003). Population and resources base of Ethiopian, 1st edition A.A Ethiopia

Collick A., (2008). Community water use in the Yeku watershed and hydrological modelling in watersheds of the upper Nile Basin, Northern Ethiopia: Dissertation, Cornell University, Ithaca, NY, USA

Degnet Abebaw (2011). Access to Improved Water Source and Satisfaction with Services, Evidence from Rural Ethiopia. Development Strategy and Governance Division, International Food Policy Research Institute Ethiopia Strategy Support Program II, Addis Ababa, Ethiopia.

Mengesha A, Abera K, Mesganaw F., (2003). Sustainability of drinking water supply projects in rural of north Gondar, Ethiopia. Ethiopian Journal of Health Development 3: 221-229.

UNDP, (2006b). Human Development Report beyond Scarcity: Power, Poverty and the Global water Crisis

WHO (2000). Global Water Supply and Sanitation Assessment 2000 Report. World Health Organization and United Nations Children's Fund 2000. New York, USA

Wonduante Shemelash (2013). Assessing the challenges of sustainable Water supply in Gondar town, Ethiopia. WUP (2003). Better Water and Sanitation for the urban poor. Good practice document from sub Saharan Africa. Water Utility Partnership for Capacity Building in Africa.Nairobi, Kenya.

WMO \& National Meteorology Agency, 2013.

Yibeltal Bantie (2011). The value of improved water supply in Eastern Gojjam. AddisAbaba, Ethiopia 